\title{
Assessing Management of Plastic Straws Attached with used Beverage Cartons - A Case Study of 3 Metropolitan Cities of India
}

\author{
Sourabh Manuja \\ Fellow, Environment and Waste Management Division, \\ The Energy and Resources Institute, Indian Habitat Centre, \\ Lodhi Road, New Delhi- 110003, India
}

\author{
Suneel Pandey \\ Director, Environment and Waste Management Division \\ The Energy and Resources Institute, Indian Habitat Centre, \\ Lodhi Road, New Delhi- 110003, India
}

\author{
Ankita Bhatia \\ Intern, Environment and Waste Management Division \\ The Energy and Resources Institute, Indian Habitat Centre, \\ Lodhi Road, New Delhi- 110003, India \\ And Student of M.Sc., Department of Environmental Science, Amity University, Noida-, \\ Uttar Pradesh-201313, India
}

\begin{abstract}
The global plastic production has increased from 1.5 Million Metric Tonnes (MMT) in 1950 to 359 MMT in 2018 and overall around 8.3 Billion Metric Tonnes of virgin plastics have been produced worldwide. Globally, only $9 \%$ produced plastic was recycled and $12 \%$ went into thermal recovery routes. Indian plastic consumption is estimated to be 20 MMT by end of 2020 with about $39 \%$ of total plastics being consumed for packaging. India's growth rate of plastic consumption is one of the highest in the world, due to rising middle class income group.
\end{abstract}

In 2017-18, India generated 9.49 MMT of plastic waste and during 2016-17, about 5.5 MMT of plastics was reported to be recycled, involving direct employment to more than 0.6 million people and more than 01 million people indirectly, including waste pickers. This reflects a dependency between recycling and socio economic development, leading towards sustainability in use of plastics. Though, a very small portion of these plastics by weight, plastic straws have been in demand for its convenience to consumers in beverage consumption. These straws are widely known for providing hygienic way for beverage consumption. Further, though being $100 \%$ recyclable, plastic straws recyclability rates in India remain unknown. To ascertain this, a study was conducted involving physical surveys and analysis with used beverage carton (UBC) waste generator, waste collectors, waste dealer and recycling mills to identify fate of used straws sold with non-spirit portion packs (UBCs) in three major cities which are also sales hub for beverage cartons sold by Tetra Pak - Bengaluru, Delhi and Mumbai.

The barriers that hinder in moving more plastic straws into recycling chain and perception of stakeholders on fate of plastic straws (attached to UBCs) are highlighted in this paper. Study reveals that in about $\mathbf{4 0 . 8 \%}$ cases in Bengaluru, 91.4\% in Delhi and $30.2 \%$ in Mumbai, straws remain inside Tetra Packs (UBCs) and go to recycling/recovery unit. In Delhi and Mumbai plastic straws get recycled along with UBCs and in Bengaluru they are taken out to be sent for thermal recovery at a cement plant.

This was a first of its kind of study to help formulate necessary plans and actions for improving the plastic straw collection and recyclability and guides how other producers can benefit from such studies. The study also reflected that effective behavioural change strategies through continuous and appropriate communication can help to maintain proper segregation of the plastic straws and thus eventually have better recycling of straws. Simultaneously, reducing the chain from collectors to recyclers with interventions of producer's responsibility organisations and appropriate policy measures can help increasing price value of plastic straws and make them sustainable.

Keywords-:_Plastic litter; extended producer responsibility; plastic recycling; Plastic waste management; used beverage carton

\section{INTRODUCTION}

Plastics are an integral part of our society. Around 8.3 Billion Metric Tonnes of virgin plastic have been produced worldwide since 1950 [1]. The global plastic production has increased from 1.5 Million Metric Tonnes (MMT) in 1950 to 359 MMT in 2018 [2], of which $51 \%$ of plastics production was from Asia [3]. Globally per capita average plastic consumption is around $28 \mathrm{~kg} \mathrm{c}^{-1} \mathrm{yr}^{-1}$ [4]. It is estimated that of global plastic produced, $9 \%$ was recycled and $12 \%$ gets into thermal recovery routes, pointing questions to the remaining portion being disposed in environment [5].

India, with nearly 1.3 billion population consumed around 15.5 MMT plastics in 2016-17 [6], and is estimated to touch 22 MMT plastic consumption by 2020 [4]. The average consumption is also expected to reach $20 \mathrm{kgs} \mathrm{c}^{-1} \mathrm{y}^{-1}$ by 2022 [7]. The growth rate of plastics industry in India is one of the highest in the world and this trend is expected to continue with a growing middle class consumers [8]. Packaging alone accounts for about $39 \%$ of total plastic consumption [9] and is expected to rise at a compounded annual growth rate (CAGR) of $10.5 \%$ from year 2015 to 2020 [4]. Indian region wise plastic consumption in Western, Northern, Southern, and Eastern are 47\%, 23\%, $21 \%$ and $9 \%$ respectively [10]. 
The total plastic waste generated in India for year 20172018 was estimated as 26,000 Tonnes Per Day (TPD), out of which about $60 \%$ of the plastic waste estimated to be recycled, mostly in informal sector [11] [12]. Out of the total plastic waste generated in India, Bengaluru, Delhi and Mumbai accounts for 313.87 TPD, 689.52 TPD and 408.27 TPD respectively [13]. The total plastic waste amount in India is also expected to increase by more than 5 times by 2041 [14].

In India, Polyethylene Terephthalate (PET) accounts for 9\%, High density Polyethylene/Low density Polyethylene (HDPE/LDPE) accounts for 66\%, Polyvinyl Chloride (PVC) accounts for $4 \%$, Polypropylene (PP) accounts for $10 \%$, Polystyrene (PS) accounts for 5\%, and other unclassified plastics/ Non-Recycling plastics/ Rubbers etc account for $6 \%$ of the total plastic demand [15]. Approximately $94 \%$ of these are thermoplastics, which can be recycled. However, economy drives recycling in India, mostly through informal sector.

It is also important to note that plastic recycling industry during 2016-17, recycled about 5.5 MMT of plastics, with more than 3500 organised recycling units and 4000 unorganised recycling units. This gave direct employment to more than 0.6 million people and more than one million indirect people, including waste pickers [6]. Demonstrating that increasing recycling of plastics and putting it into circular economy loops can help increase sustainability of plastics. This will also help in creating more green jobs, reduce plastic pollution and help conserve energy throughout the globe.

Though, a very small portion of this plastics by weight, plastic straws have been in demand for its convenience to consumers in beverage consumption, especially for creating accessibility to drink for certainly elderly or differently abled individuals. These straws are widely known for providing hygienic way for beverage consumption.

However, estimates reveal that there are 8.3 billion plastic straws dispersed globally along coastlines, which accounts for about $0.03 \%$ of 8.8 MMT plastic waste entering oceans by weight [16]. Of the plastics that enter in marine environment, almost $60 \%$ of the mismanaged plastic waste arises from East Asia \& Pacific, and Europe \& Central Asia account for only $3.6 \%$ [17]. Further, being $100 \%$ recyclable by material, plastic straws recyclability rates in India remain unknown.

With an objective to identify the rates of plastic straw getting recycled or recovered and ways with which the recyclability rates can further be enhanced, making these straws sustainable, in 3 major cities of Bengaluru, Delhi and Mumbai a study was conducted from December 2019 to March 2020. This is a first of its kind of study, and involved physical surveys and analysis with various stakeholders in the value chain of plastic straw recycling.

\section{MATERIALS AND METHODS}

With a motive to assess the value chain of straws attached to UBCs across regions in India, surveys were conducted in three major beverage carton consumption hubs, Delhi in North India, Bengaluru in South India, and Mumbai in West India.
Of the beverage cartons sold in India by Tetra Pak India Limited, approximately $50 \%$ are non-spirit portion packs (up to $250 \mathrm{ml}$ packs) which are sold with straws attached to them. In 2019 Bengaluru, Delhi and Mumbai, reported 2223 Tonnes, 2530 Tonnes and 1520 Tonnes of non-spirit portion packs (beverage cartons) being sold respectively. The UBCs getting collected and recycled in Bengaluru, Delhi and Chennai from previous study were identified as $100 \%$, $37.91 \%$ and $65.24 \%$ respectively [18].

To analyse the value chain of straws attached to UBCs and help increase recycling of straws in the country, this study was conducted by The Energy and Resources Institute (TERI). The overall approach for the study involved reviewing of existing regulations, waste quantities and waste management practices including those that are already implemented, primary survey and critical analysis of the straw (attached to UBCs) and recycling value chain associated with it. The overarching objective of this study was to explore the perceptions of stakeholders in value chain of plastic straws such as waste generators, waste collectors, waste dealers and recyclers on the fate of straws attached to portion packs and associated challenges.

This study involved- primary surveys with a questionnaire prepared to capture the fate of straws generated and collected, reasons for non-collection and possible motivations for increasing the recycling rates. To estimate the amount of straws that get along with portion packs to recycling mills, analysis were done at large scale dealers dealing with used beverage cartons. The challenges faced by the value chain stakeholders and fate of straws sent to recyclers (along with portion packs) were also assessed.

At each city, waste generators, waste collectors, large scale UBC waste dealer were interviewed. Recyclers, one in Uttarakhand (North India) and another at Palgarh, Maharashtra (West India) receiving UBC were also surveyed and interviewed to understand the ultimate fate of straws.

At waste dealer level, for calculating sample size (n) which can give $>90 \%$ confidence level with an acceptable $10 \%$ margin of error Cochran's formula for finite population size was adopted. The number of waste non spirit portion packs (UBCs) received with straw to be analysed were evaluated using this formula [19].

Equation 1

$$
\mathrm{n}=\frac{\mathrm{n}^{\circ}}{1+\frac{\left(\mathrm{n}^{\circ}-1\right)}{\mathrm{N}}}
$$

Where,

$$
\begin{aligned}
& \mathrm{n}=\text { sample size } \\
& \mathrm{N}=\text { population size }=144 \\
& n^{\circ}=\frac{Z^{2} p q}{e^{2}} \\
& \mathrm{Z}=\text { selected critical value of desired }
\end{aligned}
$$

confidence level $=1.64$

$$
\mathrm{p}=\text { estimated proportion of an attribute }
$$
that is present in the population $=0.5$

$$
\begin{aligned}
& \mathrm{q}=1-\mathrm{p}=0.5 \\
& \mathrm{e}=\text { desired level of precision }=0.1
\end{aligned}
$$

Table 1 indicated the amount of UBCs sold, non-spirit portion packs sold and size of sample required to analyse status of straw collected with portion packs. 
TABLE 1: SAMPLE SIZE CALCULATION BASED ON COCHRAN'S FORMULA

\begin{tabular}{|l|l|l|l|l|}
\hline City & $\begin{array}{l}\text { Beverage cartons } \\
\text { sold in 2019 (kgs) }\end{array}$ & $\begin{array}{l}\text { Non spirit portion } \\
\text { packs sold in 2019 (kgs) } \\
\text { approx. 50\%) }\end{array}$ & $\begin{array}{l}\text { Average portion cartons sold } \\
\text { per day in 2019 (kgs) }\end{array}$ & $\begin{array}{l}\text { Sample size required for >90\% } \\
\text { confidence level and 10\% acceptable } \\
\text { margin of error (kgs) }\end{array}$ \\
\hline Bengaluru & 4447000 & 2223500 & 6092 & $>67$ \\
\hline Delhi & 5061000 & 2530500 & 6933 & $>67$ \\
\hline Mumbai & 3041000 & 1520500 & 4166 & $>67$ \\
\hline
\end{tabular}

This analysis revealed that more than $67 \mathrm{kgs}$ of non-spirit portion packs at waste dealer level were to be analysed, to understand the percentage arriving with straws in them. For primary survey, stakeholders mapping was done and stakeholders were interviewed which were spread out in the city.

Based on field survey, literature review and analysis of collected data, this study analyse the fate of straws attached Used Beverage cartoons (non-spirit portion packs) and identifies gaps in exiting system, to prepare strategies to bring them back to circular economy loop and make product sustainable.

\section{RESULTS AND DISCUSSIONS}

When a beverage carton is disposed after use from a generator's end, it will either move towards recycling route with mixed paper or separately, or if gets disposed with MSW as waste. When this UBC enters recycling loop, it passes through a chain involving waste collectors, who either collect segregated UBCs or UBCs along with mixed waste paper to sell it to a large scale dealer. The large scale dealer further sends these accumulated UBCs to recyclers to make several of products such as Kraft paper and compressed boards.

The survey of 10 waste generators in each city, which were mostly market and institutions who were generating
UBCs, revealed that $100 \%$ in Bengaluru, $20 \%$ in Delhi and only $10 \%$ in Mumbai were segregating their waste into wet and dry waste at source. About $80 \%$ generators in Bengaluru, $50 \%$ in Delhi and $100 \%$ in Mumbai were disposing their UBCs along with municipal waste only. Only $20 \%$ generators in Bengaluru, $40 \%$ generators in Delhi were selling UBCs. However, of total surveyed $10 \%$ waste generators in Delhi used to mix UBC's (including portion packs) with mixed paper waste and then sell it. About $90 \%$ waste generators in Bengaluru, 80\% in Delhi and Mumbai each were unaware about the recyclability of plastic straws and the economics involved it. However, the generators who were aware about straw recycling made no efforts to separate straws from UBC's. Also, the waste generators in Bengaluru, Delhi and Mumbai unanimously agreed that the straw remain inside UBC's at the time of their disposal. In all the three cities, the selling price of mixed paper waste varied from Rs $3 \mathrm{~kg}^{-1}$ to Rs $7 \mathrm{~kg}^{-1}$, cardboard waste varied from Rs $2 \mathrm{~kg}^{-1}$ to $\mathrm{Rs} 7 \mathrm{~kg}^{-1}$ and plastic waste varied from Rs $4 \mathrm{~kg}^{-1}$ to $\mathrm{Rs} 10 \mathrm{~kg}^{-1}$.

The survey of 20 waste collectors in each city, spread over different areas involved a mix of door to door collector and rag pickers, with about $5 \%$ collectors surveyed in Delhi and $10 \%$ in Mumbai as rag pickers. Fig 1 shows the recyclable materials collected by waste collectors.

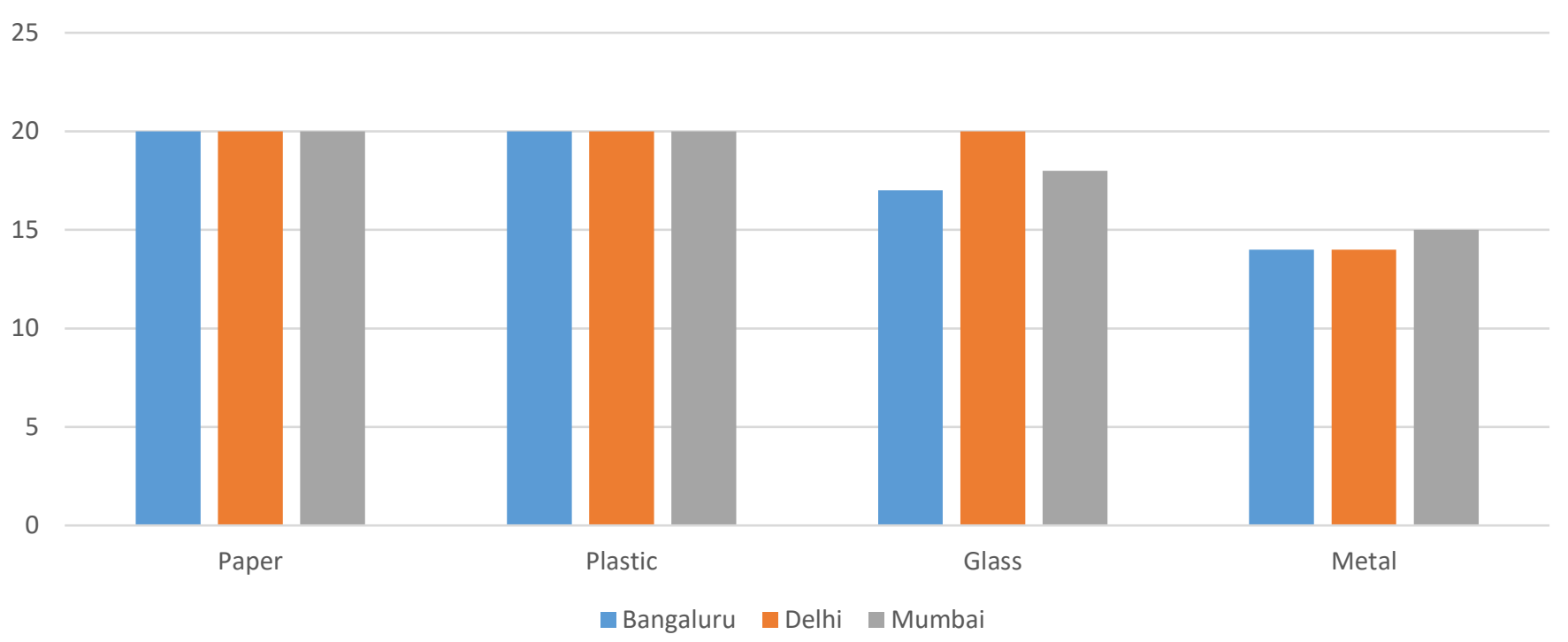

FIGURE 1: TYPE OF RECYCLABLES COLLECTED BY WASTE COLLECTORS IN SURVEY CITIES

About $95 \%$ waste collectors in Bengaluru collect UBC's, out of which $79 \%$ get straws inside UBC's and the remaining $21 \%$ only collect spirit portion packs (UBC's sold without straw) and hence do not receive straws, wherein all collectors in Delhi and Mumbai collect UBC's with straws inside them. It was also identified that $13 \%$ waste collectors in Bengaluru (as dealer wants them to), $5 \%$ in Delhi and 5\% in Mumbai separate straws from non-spirit portion packs for recycling (at $3 \mathrm{Rs} \mathrm{kg}^{-1}$ in Delhi). Whereas remaining waste 
collectors were of the opinion that straws also remain inside UBCs only.

Almost none of waste collector in Bengaluru and Mumbai were aware about plastic straw recyclability, In Bengaluru straw was removed as paper mill accepting UBCs used to reject portion packs coming along with straws. Only $10 \%$ in Delhi were aware about plastic straws recyclability.
About $10 \%$ waste collectors in Bengaluru and $30 \%$ in Delhi were of the opinion that straws can be collected if there is a market for straws upto $8 \mathrm{Rs} \mathrm{kg}^{-1}$ and $10 \mathrm{Rs} \mathrm{kg}^{-1}$ respectively. When asked of possible reasons why waste collectors cannot collect straws for recycling, they has multiple answers, as shown in Fig 2

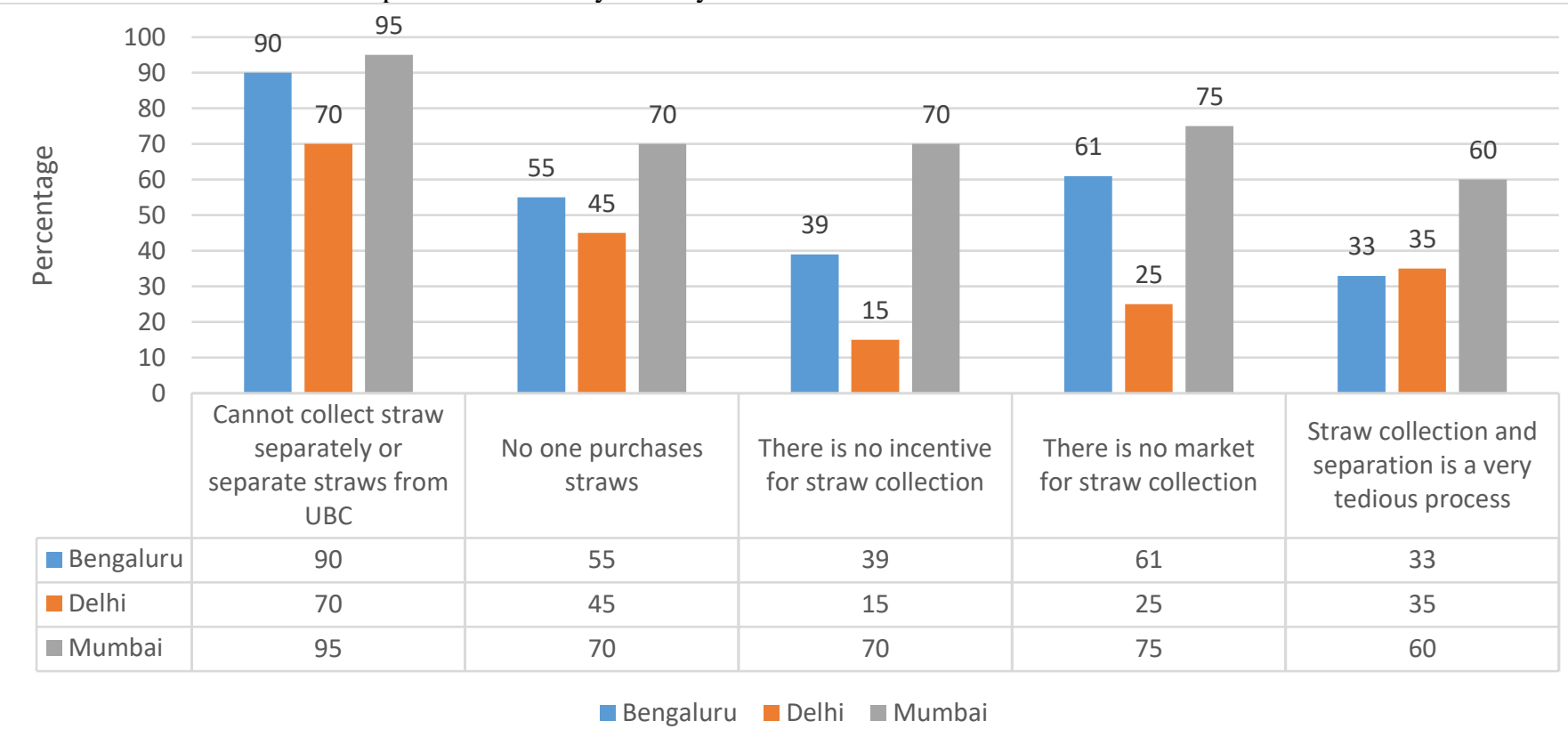

FIGURE 2: POSSIBLE REASONS AMONG WASTE COLLECTORS FOR NOT SHOWING INTEREST IN STRAW COLLECTION.

. In Bengaluru 5\%, in Delhi 75\% and in Mumbai $75 \%$ waste collectors collect recyclables and sell to a particular waste dealer only, whereas remaining sell their recyclables to different dealers depending on offered price. The offer price range of recyclables in the three cities have been shown in Fig 3.

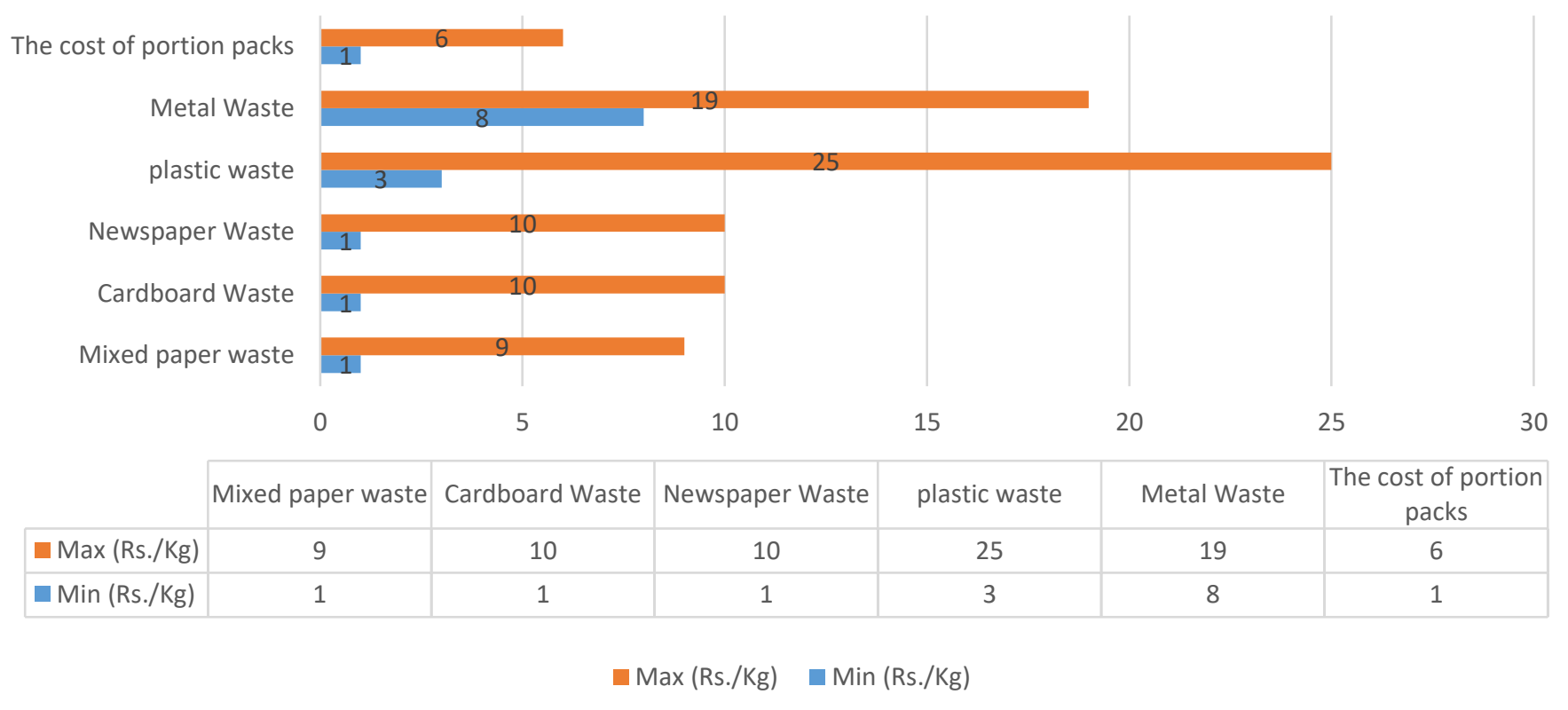

FIGURE 3: PRICE RANGE OF RECYCLABLES IN SURVEYED CITIES 
When asked about where the straws end up, $75 \%$ in Delhi and $80 \%$ in Mumbai said that they remain inside UBC's and get disposed with mixed waste. About $50 \%$ waste collectors in Bengaluru and $10 \%$ in Mumbai said that they are disposed with MSW.

The survey at large scale waste dealers dealing in UBC waste revealed, in Bengaluru nearly 18-20 small scale dealers; in Delhi about 100-200 waste collectors and in Mumbai about 150 societies and institutions were handing over waste to them. Waste dealer in Bengaluru, Delhi and Mumbai were dealing in $45 \mathrm{MT}, 40 \mathrm{MT}$ and 3.0 MT of UBCs per month respectively.

The dealers in Delhi had an opinion that most of the UBCs (portion packs) contain straws within them. However, they also agreed that there exists a separate market for straws attached to portion packs, but collectors still do not segregate straws. However, the prices of plastic straw were earlier Rs $15 \mathrm{~kg}^{-1}$. Whereas, in Bengaluru the dealer informed that there is no separate market for straws and since the tentative ban on single use plastics (SUP) was envisaged by the Government of India, the price of mixed plastic waste (other than PET bottles) had gone down and as a result, no rag picker collected straws. Whereas in Mumbai waste dealer had an opinion that there is no separate market for straws but the few dealers buy them with other plastics at a price of around Rs $10 \mathrm{~kg}^{-1}$.

Waste dealers in Delhi and Mumbai had an opinion that the effort required to separate the straws from portion packs is not worth the current price of straws, making their segregation at collectors/dealers level economically unfeasible. In Delhi, the large-scale dealer sends the entire UBC waste load with straw inside to paper mill in Uttarakhand for recycling and further processing at INR 5.5 $\mathrm{kg}^{-1}$. In Bengaluru, the large scale waste dealer segregates and removes straws from portion packs before baling, which is disposed as alternate fuel and raw material (AFR) in cement plants located at Wadi, Gulbarga, Karnataka, for a price of INR $2 \mathrm{~kg}^{-1}$. The UBCs are sold to paper mill at INR $6.5 \mathrm{~kg}^{-1}$, which do not accept plastic straws with UBCs. Whereas in Mumbai, straws are not removed and entire UBC waste load is sent for recycling at INR $13 \mathrm{~kg}^{-1}$.

The analysis of non-spirit portion packs (UBCs) at waste dealer level revealed that of the collected portion packs by the waste dealer, $40.8 \%$ are portion packs with straws in Bengaluru, $91.4 \%$ are portion packs with straws in Delhi and $30.2 \%$ in Mumbai.

To identify the fate of UBCs that are sent to paper mill, surveys were done, identifying the final fate of collected straws. For North India, paper mill in Uttarakhand was surveyed, having an annual paper manufacturing capacity of 30,000 MT which receive around 3000 Tonnes per annum of UBCs. This UBCs were mixed with other waste papers to manufacture Kraft paper (manufactured about 12000-14400 Tonnes per annum). There was no difference in price of portion packs if it comes with straw or without straw. The unit has a pulper unit (boiler) which extracts pulp out of UBCs and screened rejects are collected for further handling by plastic pellet unit. After drying, all plastic reject is converted into aglo resins by increasing the temperature and maintaining it. These aglo resins are then sent for injection moulding (via extruder) and the final pellets are yielded. These pellets are further sold to market at $15-16 \mathrm{Rs} \mathrm{kg}^{-1}$.

For Western India, a recycling unit in Palgarh, Maharashtra was surveyed which receive around 13200 Tonnes per month of waste materials, out of which $60 \%$ are UBCs received from residential, commercial and consumer rejects from across West and South India. The purchase price for UBCs were around Rs. $8-9 \mathrm{~kg}^{-1}$. The materials received are compressed under pressure to form compressed sheets, which are used to make compressed sheets, which form furniture in automotive and commercial markets. They had no rejects from the process and the cuttings are reused to make products again via heat press. The press heats up the straws which starts melting and helps in binding the materials together. There are no straw waste rejects from the unit. Hence all straws which come along with portion packs get recycled fully to be made into compressed boards.

\section{CONCLUSION}

This was a first of its kind of study conducted in the three metropolitan cities like Bengaluru, Delhi and Mumbai and it helped the stakeholders to formulate necessary plans and actions for improving the plastic straw collection and recyclability. The three cities surveyed depicted almost similar straw management practices by different stakeholders. Waste generators interviewed reported of straw disposal along with portion packs. The waste collectors reported of sending the portion packs along with the straws to the large-scale dealer. In all the cities, at higher stakeholder level, i.e. the large-scale dealer, the straws are reported to come along with the portion packs. Dealers at Bengaluru and Mumbai, refused from buying straws separately, as they deal with waste paper only. Plastic waste management rules 2016, even being enforced by the government, were not followed by the waste generators. There is a need to concentrate further on the behaviour change of stakeholders like waste generators and collectors. Effective behavioural change strategies can help to maintain proper segregation of the plastic straws and thus eventually will also have positive effect on the recycling of straws. Methods of encouragement can be utilized by praising the front leaders in the system and fining the defaulters. Additional steps should also be taken to boost the collection rates of UBCs in the three cities. Awareness and knowledge should be spread among the consumers to put back the straw in packs before their disposal. Waste producers and waste collectors understood nothing about the recycling opportunities and economics involved in straws, and even though few of them knew they were reluctant to put extra effort into straw separation. Awareness drives must be run by Local NGOs of cities to spread awareness, information and linkages among each of the stakeholders.

There is a further need to get the UBCs into active recycling chain as this will not only increase the market potential but will also reduce the number of stakeholders involved in recycling chain. This will increase the price value for those on the front end of the recycling value chain i.e. waste collectors. 
Effective collection of UBCs and tie up with recycling systems will help drive the collection and recycling of UBCs back into these communities. The acceptance of UBCs by paper mills is the first primary imperative which can help to increase the acceptability of UBCs among waste dealers. This will require information, education and capacity building activities with paper mills along with a strong business case that depicts profitability scenarios through fibrous content of paper based UBCs.

To encourage the active recycling of UBCs, a separate collection centre should be built for UBCs which should be linked to material recovery facilities (existing/coming under Solid Waste Management Regulations 2016).

Higher UBC prices can drive informal recycling effectively and increase the recycling rates. Higher prices can be achieved either by reducing the chain for recycling and collection or by upcycling UBCs.

The management of UBC's should be examined more, and positive lessons should be repeated at other places.

\section{ACKNOWLEDGMENT}

We would like to express our sincere gratitude towards Tetra Pak India Pvt Ltd for sponsoring this study via blanket order 919473822. We also thank Ms. Twinkle Dev and Mr. Andullah Atiq who were involved in conducting field surveys in the selected cities on behalf of TERI.

\section{REFERENCE}

[1] R. A. Meidl, "Plastic Waste Management: Are We on the Right Path to Sustainability?," Rice University's Baker Institute For Public Policy, 2018

[2] M. Garside, "Global plastic production statistics," 8 November 2019 [Online]. Available: https://www.statista.com/statistics/282732/global-production-ofplastics-since-1950/. [Accessed 12 May 2020].

[3] Plastics Europe, "Plastics - the Facts 2019 An analysis of European plastics production, demand and waste data," Carbon Neutral, Brussels, Belgium, 2019.

[4] Federation of Indian Chambers of Commerce and Industry, "3 National Conference on sustainable infrastructure with plastics," in Knowledge Paper on Plastic Industry for Infrastructure, New Delhi, 2017.

[5] J. N. Gutierrez, A. W. Royals, H. Jameel, R. A. Venditti and L. Pal, "Evaluation of Paper Straws versus Plastic Straws: Development of a Methodology for Testing and Understanding Challenges for Paper Straws," p. 8345, September 2019.

[6] PlastIndia, "Report on The Indian Plastics Industry," Plastindia Foundation, 2018.

[7] "Fact Sheet on plastic waste in India," 2018.

[8] Toxic Link, "Single Use Plastics The Last Straw," Toxic Link, New Delhi, 2020.

[9] Federation of Indian Chambers of Commerce and Industry, "2nd National Conference: Plastic Packaging- The Sustainable Choice," Delhi, 2016.

[10] Federation of Indian Chambers of commerce and Industry, "Potential of plastic industry in northern India with special focus on plasticulture and food processing," FICCI, New Delhi, 2014.

[11] Central Pollution Control Board, "Assessment \& Characterisation of Plastic Waste Generation in 60 Major Cities," New Delhi, 2015.
[12] S. Henam, "Can plastics be good?," 25 November 2018. [Online]. Available: https://www.downtoearth.org.in/reviews/can-plastics-begood--62112. [Accessed 15 May 2020].

[13] Central Pollution Control Board, "Assessment \& Characterisation of Plastic Waste Generation in 60 Major Cities," 2015.

[14] Statista, "Plastic waste generated in India 2001-2041," 23 September 2019. [Online]. Available: https://www.statista.com/statistics/1009095/india-plastic-wastegeneration/. [Accessed 15 May 2020].

[15] Central Pollution Control Board, "Assessment \& Quantification of Plastics Waste Generation in Major Cities," Delhi, 2015.

[16] R. A. MEIDL, Plastic Waste Management:Are We on the Right Path to Sustainability?, Houston: Rice University's Baker Institute for Public Policy, 2018.

[17] H. Ritchie and M. Roser, "Plastic Pollution," Our World in Data, Sepetember 2018.

[18] The Energy and Resources Institute, "USED BEVERAGE CARTON (UBC) MANAGEMENT STUDY FOR INDIA," The Energy and Resources Institute, New Delhi, 2019.

[19] W. G. COCHRAN, Sampling Techniques, Third Edition, John Wiley \& Sons, 1977. 